\title{
Spectro-microscopic measurements of carbonaceous aerosol aging in Central California
}

\author{
R. C. Moffet ${ }^{1,2}$, T. C. Rödel ${ }^{1,3}$, S. T. Kelly ${ }^{1}$, X. Y. Yu ${ }^{4}$, G. T. Carroll ${ }^{1}$, J. Fast ${ }^{4}$, R. A. Zaveri ${ }^{4}$, A. Laskin ${ }^{5}$, and \\ M. K. Gilles ${ }^{1}$ \\ ${ }^{1}$ Lawrence Berkeley National Laboratory, Berkeley, California 94720-8198, USA \\ ${ }^{2}$ Department of Chemistry, University of the Pacific, Stockton, California 95211, USA \\ ${ }^{3}$ University of Würzburg, Department of Physics, Am Hu-bland, 97074 Würzburg, Germany \\ ${ }^{4}$ Atmospheric Sciences and Global Change Division, Pacific Northwest National Laboratory, Richland, \\ Washington 99352, USA \\ ${ }^{5}$ W. R. Wiley Environmental Molecular Sciences Laboratory, Pacific Northwest National Laboratory, Richland, \\ Washington 99352, USA
}

Correspondence to: R. C. Moffet (rmoffet@ pacific.edu)

Received: 8 February 2013 - Published in Atmos. Chem. Phys. Discuss.: 5 April 2013

Revised: 24 September 2013 - Accepted: 26 September 2013 - Published: 29 October 2013

\begin{abstract}
Carbonaceous aerosols are responsible for large uncertainties in climate models, degraded visibility, and adverse health effects. The Carbonaceous Aerosols and Radiative Effects Study (CARES) was designed to study carbonaceous aerosols in the natural environment of the Central Valley, California, and learn more about their atmospheric formation and aging. This paper presents results from spectromicroscopic measurements of carbonaceous particles collected during CARES at the time of a pollution accumulation event (27-29 June 2010), when in situ measurements indicated an increase in the organic carbon content of aerosols as the Sacramento urban plume aged. Computer-controlled scanning electron microscopy coupled with an energy dispersive X-ray detector (CCSEM/EDX) and scanning transmission X-ray microscopy coupled with near-edge X-ray absorption spectroscopy (STXM/NEXAFS) were used to probe the chemical composition and morphology of individual particles. It was found that the mass of organic carbon on individual particles increased through condensation of secondary organic aerosol. STXM/NEXAFS indicated that the number fraction of homogenous organic particles lacking inorganic inclusions (greater than $\sim 50 \mathrm{~nm}$ equivalent circular diameter) increased with plume age, as did the organic mass per particle. Comparison of the CARES spectromicroscopic dataset with a similar dataset obtained in Mexico City during the MILAGRO campaign showed that fresh
\end{abstract}

particles in Mexico City contained three times as much carbon as those sampled during CARES. The number fraction of soot particles at the Mexico City urban site (ranging from 16.6 to $47.3 \%$ ) was larger than at the CARES urban site (13.4-15.7\%), and the most aged samples from CARES contained fewer carbon-carbon double bonds. Differences between carbonaceous particles in Mexico City and California result from different sources, photochemical conditions, gas phase reactants, and secondary organic aerosol precursors. The detailed results provided by these spectro-microscopic measurements will allow for a comprehensive evaluation of aerosol process models used in climate research.

\section{Introduction}

Uncertainties in predicting future climate change are, in large part, due to an incomplete knowledge of atmospheric aerosols (IPCC, 2007). Aerosols affect climate by scattering and absorbing solar radiation (direct effect) and by modification of cloud properties (indirect effects). The direct and indirect effects are strongly dependent on the distribution of chemical species within individual particles. For example, the optical properties of strongly absorbing soot particles may change as a result of condensation of non-absorbing material that behaves as a "lens" to enhance the solar radiation 
incident on the strongly absorbing soot inclusion (Moffet and Prather, 2009; Ackerman and Toon, 1981; Jacobson, 2001; Cappa et al., 2012). If particles contain only a pure salt or organic component (external mixture), the hygroscopic properties of the population may differ from the case where the hydrophobic organic material and hygroscopic salt are within the same particle (internal mixture) (Petters and Kreidenweis, 2007; Hansson et al., 1998; Nizkorodov et al., 2010; Meyer et al., 2009). Mixing of aerosol with secondary material can also influence ice cloud formation. For example, the ice nucleating ability of mineral dust particles may be altered by reaction with sulfuric acid, which destroys nucleation sites (DeMott and Prenni, 2010; Sullivan et al., 2010). Developing accurate global climate models requires a processlevel understanding of the aerosol life cycle from initial formation to loss through their incorporation into precipitating clouds or dry deposition (Ghan and Schwartz, 2007). Such process-level understanding can only be obtained through coordinated measurements of different time and length scales from the microscopic to the synoptic.

Large, multi-institutional field campaigns allow researchers to gain a process-level understanding of the aerosol life cycle in nature through intensive complementary measurements otherwise not possible. Typically, measurements are aimed at investigating a specific process. The anthropogenic influence on climate change is an important research topic, with particular emphasis given to studying the effects of anthropogenic aerosol emissions on radiative transfer and cloud formation (Molina et al., 2007, 2010; Singh et al., 2009). These field campaigns have revealed the complexity of secondary organic aerosol formation (Jimenez et al., 2009; Volkamer et al., 2006; Zaveri et al., 2010), evolution of aerosol mixing state (Moffet et al., 2008, 2010b; Moffet and Prather, 2009; Johnson et al., 2005; Adachi and Buseck, 2008), and effects on natural precipitation patterns by changing aerosol hygroscopic and cloud nucleating properties (Knopf et al., 2010; Wang et al., 2012). Results from these field studies serve to guide the improved development of aerosol process models that can be used to test larger regional or global climate models.

In the summer of 2010, the Carbonaceous Aerosols and Radiative Effects Study (CARES) took place in the Sacramento metropolitan area and the Sierra Nevada foothills (see Fig. 1). A major research goal of CARES was to characterize secondary organic aerosol formation and its effect on the mixing state of individual particles (Zaveri et al., 2012). It is expected that as photochemical production of secondary organic aerosol proceeds, primary particles become coated with organic carbon and new, homogenous organic-rich particles become more abundant. In the Sacramento region, primary sources of particles include transportation, cooking, other biogenic sources, windblown dust, sea salt, and transport of dust mixed with secondary aerosol species from Asia (Hadley et al., 2010; Vicars and Sickman, 2011; Chen et al., 2007). Biogenic sources of organic aerosol precursors in

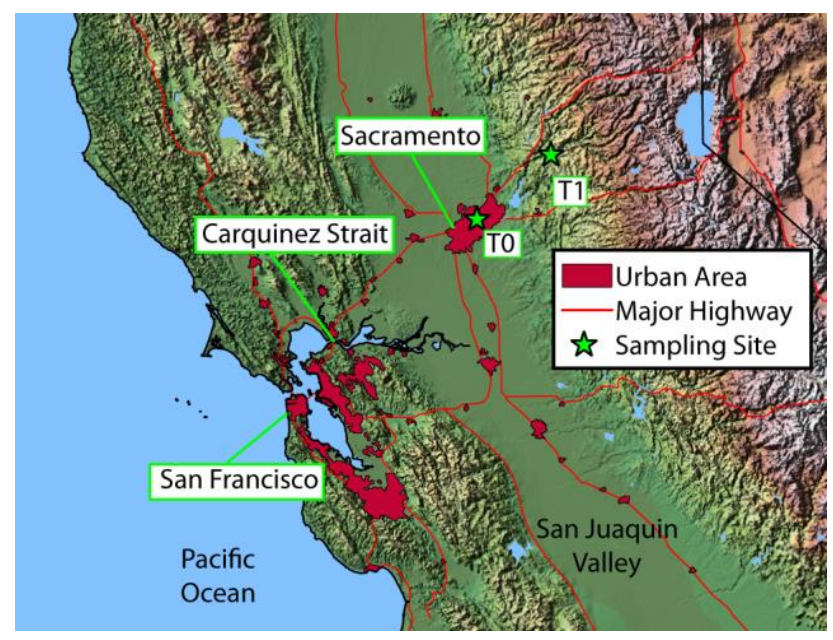

Fig. 1. Location of sampling sites and major urban areas. The urban site (T0) is located east of the Sacramento city center and the rural site (T1) is located in the Sierra Nevada foothills. The Carquinez Strait is a narrow passageway through which much of the airflow enters the Central Valley. Numerous oil refineries that emit $\mathrm{SO}_{2}$ are located along the Carquinez Strait.

the CARES study region include emissions from the forest located in the Sierra Nevada foothills or from the agricultural fields surrounding the Sacramento urban area (BouvierBrown et al., 2009; Marr et al., 2002b). Transportation is the primary source of anthropogenic VOCs in the California Central Valley (Harley et al., 2005; Marr et al., 2002a). Transport of vehicular and industrial emissions (e.g. refineries) from the San Francisco Bay Area is an important source of aerosol for the Sacramento urban area (Beaver et al., 2010). Hence, CARES provides a unique case study due to its mixture of both anthropogenic and biogenic volatile organic hydrocarbons (VOCs) that contribute to secondary aerosol formation.

This article aims to provide detailed microscopic characterization of fresh and aged aerosol during a photochemical aerosol formation event. These events are representative of stagnant conditions during the summertime in the California Central Valley. Characteristic meteorological conditions of these evens are conducive to the upslope and downslope flows that carry the urban plume from source to receptor and allow us to characterize changes in mixing state due to SOA formation. These results will be useful for evaluating particle-resolved aerosol process models. Furthermore, comparison of CARES measurements with other field campaigns offers insights into important factors affecting the molecular composition and mixing state of the atmospheric particles.

\section{Experimental}

Microscopic methods are utilized in this study to determine the mixing state of individual particles. In this section, 
particle collection methods and microscopic analysis techniques are described.

\subsection{Sampling}

During the CARES campaign, microscopy sampling was carried out at the T0 $\left(38^{\circ} 38^{\prime} 55.5^{\prime \prime}, 121^{\circ} 20^{\prime} 59.02^{\prime \prime}\right)$ and T1 $\left(38^{\circ} 52^{\prime} 17.02^{\prime \prime}, 121^{\circ} 1^{\prime} 21.59^{\prime \prime}\right)$ sites indicated in Fig. 1. The sampling sites were selected to capture the aging of the urban air mass as it was transported from Sacramento (T0) to the foothills of the Sierra Nevada mountains (T1). At both sampling sites, a large number of instruments were deployed to observe the transformation of the urban air mass (Zaveri et al., 2012). All times reported in this manuscript are local standard time (LST).

Time-resolved aerosol collectors (TRACs) were deployed at the $\mathrm{T} 0$ and $\mathrm{T} 1$ sites and collected particles onto microscopy substrates by inertial impaction. The samplers held several substrates for different analysis methods: $3 \mathrm{~mm} \times 3 \mathrm{~mm}^{2} \mathrm{Si}$ wafer chips for ice nucleation studies, copper-grid-supported carbon B films, and silicon nitride $\left(\mathrm{Si}_{3} \mathrm{~N}_{4}\right)$-coated $\mathrm{Si}$ frames for X-ray microscopy. Every $20 \mathrm{~min}$, the substrates were automatically advanced for the deposition of ambient particles. The $50 \%$ cut-off diameter of the TRAC sampler is about $0.35 \mu \mathrm{m}$, although particles from 150 to $3000 \mathrm{~nm}$ are routinely sampled. Additional details of the TRAC samplers have been described elsewhere (Laskin et al., 2003, 2006).

\subsection{CCSEM/EDX measurements}

A FEI Quanta digital field emission gun environmental scanning electron microscope was used in this work. The microscope is equipped with an EDAX X-ray spectrometer with a $\mathrm{Si}(\mathrm{Li})$ detector with an active area of $10 \mathrm{~mm}^{2}$ and an ATW2 window. During CCSEM/EDX operation mode, selected sample areas are inspected and particles are identified. Then, X-ray spectra are acquired for all detected particles. In this work, particles with an equivalent circular diameter larger than $0.1 \mu \mathrm{m}$ were measured. In this paper, the coarse mode is defined as all particles larger than $1 \mu \mathrm{m}$ and the fine mode is defined as all particles less than $1 \mu \mathrm{m}$. The X-ray spectra were acquired for $10 \mathrm{~s}$, at a beam current of $500 \mathrm{pA}$ and an accelerating voltage of $20 \mathrm{kV}$. The elements considered in the X-ray analysis were $\mathrm{C}, \mathrm{N}, \mathrm{O}, \mathrm{Na}, \mathrm{Mg}, \mathrm{Al}, \mathrm{Si}$, $\mathrm{P}, \mathrm{S}, \mathrm{Cl}, \mathrm{K}, \mathrm{Ca}, \mathrm{Mn}, \mathrm{Fe}$, and $\mathrm{Zn}$. Additional details of the CCSEM/EDX analysis of particles deposited onto carboncoated TEM grids can be found in Laskin et al. (2006) and references therein. K-means cluster analysis was carried out using the Matlab (Mathworks, Natick, MA) implementation of the K-means clustering algorithm (Seber, 1984; Spath, 1985). Individual particle EDX spectra were pre-processed by removing elements having less than 0.5 atomic $\%$.

\subsection{Scanning transmission X-ray microscopy/near- edge $X$-ray absorption fine structure spectroscopy (STXM/NEXAFS)}

STXM/NEXAFS measurements were carried out at Lawrence Berkeley National Laboratory's Advanced Light Source. The Advanced Light Source is a high-brightness synchrotron source of $\mathrm{X}$-ray radiation. This radiation is produced using insertion devices (bending magnets or undulators), directed down a "beamline", energy selected with a monochromator, and focused at the microscopy endstations, where the sample is raster-scanned at the focal point. Typical beam diameters can be focused to $\sim 30-35 \mathrm{~nm}$ using a Fresnel zone plate. X-rays transmitted through the sample are detected with a phosphor-coated Lucite pipe coupled to a photodiode detector. STXM/NEXAFS microscopes at beamlines 11.0.2 and 5.3.2 were used to analyze the samples in this study. The details of these instruments may be found elsewhere (Kilcoyne et al., 2003).

STXM/NEXAFS data are typically acquired by raster scanning the sample at a fixed energy and simultaneously detecting the light transmitted through the sample. The light from sample free regions is the reference intensity $\left(I_{0}\right)$, and light transmitted through the sample is taken as the sample intensity $(I)$. The transmitted light is transformed into optical density using Beer's law: $\ln \left(I / I_{0}\right)=-\mu \rho t$, where $\mu$ is the mass absorption coefficient, $\rho$ is the density and $t$ is the sample thickness. Spectral images ("stacks") are acquired by using two-dimensional images of a fixed region over multiple energy values. Sampled energy ranges are chosen to sufficiently characterize the absorption "edge" of some element (typically carbon). The fine structure within the absorption edge is indicative of oxidation state and chemical bonding of the particular element being probed. Thus, STXM/NEXAFS is capable of providing chemical bonding for carbon and other "light elements" - including nitrogen and oxygen - at a spatial resolution of $35 \mathrm{~nm}$ (Moffet et al., 2011). For the T0 site 2426 particles were analyzed and for the T1 site 3457 particles were analyzed.

\subsection{Sunset OCEC analyzer}

Two semi-continuous Sunset OCEC analyzers (Model 3F, Sunset Laboratory Inc., Portland, OR) were used to measure organic carbon (OC) and elemental carbon (EC) mass loadings at the T0 and T1 sites. Ambient samples were collected continuously by drawing a sample flow of $\sim 8 \mathrm{lpm}$. A cyclone was used upstream of the instruments to pass particles smaller than $2.5 \mu \mathrm{m}$. The airstream also passed through a denuder to remove any volatile organic compounds in the air. Sample flow rate was adjusted for the pressure difference between sea level and each of the sites to ensure accurate conversion of sample volume. During automated semicontinuous sampling, particulate matter was deposited on a quartz filter. 
After a sample was collected, an in situ analysis was conducted by using the modified NIOSH method 5040, i.e., thermal optical transmittance analysis, to quantify OC and EC. The oven was first purged with helium after a sample was collected. The temperature inside the oven was ramped up in a step fashion to $870^{\circ} \mathrm{C}$ to thermally desorb the organic compounds. The pyrolysis products were converted to carbon dioxide $\left(\mathrm{CO}_{2}\right)$ by the redox reaction with manganese dioxide. The $\mathrm{CO}_{2}$ was quantified using a self-contained nondispersive infrared (NDIR) laser detection system. To quantify EC using the thermal method, a second temperature ramp was applied while purging the oven with a mixture containing oxygen and helium. During this stage, the elemental carbon was oxidized and the resulting $\mathrm{CO}_{2}$ was detected by the NDIR detection system. At the end of each analysis, a fixed volume of external standard containing methane $\left(\mathrm{CH}_{4}\right)$ was injected and thus a known carbon mass could be derived. The external calibration was used in each analysis to ensure repeatable quantification. The modified NIOSH thermal-optical transmittance protocol used during CARES has been summarized elsewhere (Yu et al., 2009).

\subsection{Meteorology}

The sampling period from 27 to 28 June 2010 was selected due to the ideal flow condition for transport from $\mathrm{T} 0$ to $\mathrm{T} 1$ as well as high temperatures and high organic aerosol loadings. Prior to 27-28 June, a series of troughs passed over California, creating strong winds that quickly carried pollutants out of the sampling region. After a third and much weaker trough passed on 21 June, winds became light and variable, and temperatures on the 27th and 28th were the warmest days of the campaign with highs of $\sim 40^{\circ} \mathrm{C}$ (Fast et al., 2012). Ozone generally increased after passage of the third trough and reached $90 \mathrm{ppb}$ on the 28th, indicating active photochemistry and an accumulation of pollutants. Carbon monoxide tracer modeling suggested that between 40 and $80 \%$ of the $\mathrm{CO}$ concentration at $\mathrm{T} 0$ during the evening and early morning on both days was due to sources located in the San Francisco Bay Area, decreasing to roughly $30 \%$ as the boundary layer increased and as Bay Area CO was transported beyond Sacramento. A similar temporal variation of $\mathrm{CO}$ originating from the Bay Area was simulated at the T1 site; however, emissions from Sacramento and local sources along the foothills contributed the largest fraction of CO. Therefore, Bay Area urban sources are expected to play a significant role in the overall pollution levels in the Sacramento region during the 27-28 June time period.

\section{Results}

\subsection{Characteristics of the 27-28 sampling period}

Results from the CO tracer forecasts shown in Fig. 2 illustrate the motion of all the urban emissions from 07:00 to
12:00 PDT. Early in the morning, the boundary layer in the Central Valley was below the T1 site as indicated by the tracers being concentrated over the T0 site. As the boundary layer grew and upslope flow developed, pollutants were transported towards the $\mathrm{T} 1$ site. The tracer forecasts shown in Fig. 2 were directly evaluated with aircraft measurements of CO. Generally, excellent agreement was seen between the tracer forecasts and the aircraft measurements (Fast et al., 2012).

Figure 3 displays the time series for organic aerosol mass determined by a thermo-optical analyzer. The T0 site saw more pronounced diurnal variations in organic aerosol levels compared to $\mathrm{T} 1$. The time series of particulate organic carbon at both $\mathrm{T} 0$ and $\mathrm{T} 1$ indicate an accumulation of organic aerosol mass over the two-day time period from 27 to 28 June. Aerosol mass spectrometry measurements at T1 are in general agreement with the Sunset field analyzer, albeit with more pronounced diurnal trends due to its higher temporal resolution (Setyan et al., 2012). Nevertheless, aerosol mass spectrometry data also indicate a similar buildup at $\mathrm{T} 1$ as indicated by the organic aerosol data in Fig. 7 (Zaveri et al., 2012). Combining measurements of meteorology and particulate organic carbon, it is apparent that 27-28 June serves as a good time period to microscopically study the transformation of individual organic particles undergoing photochemical aging. The vertical lines in Fig. 3 indicate time periods where microscopy samples were analyzed by CCSEM/EDX (green) and STXM/NEXAFS (red).

\subsection{Chemical imaging of particles by CCSEM and STXM/NEXAFS}

Single energy STXM images, NEXAFS spectra and component maps of particles collected during time periods of low and high organic aerosol concentration are displayed in Fig. 4. X-ray images at $278,285.1$ and $288.7 \mathrm{eV}$ provide optimum contrast for non-carbonaceous inorganic species, soot and organic carbon, respectively. Figure 4 demonstrates that well-defined peaks of carbonate $\left(\mathrm{CO}_{3}\right)$ and potassium $(\mathrm{K})$ were also observed. Spectral images provided by STXM/NEXAFS were used to map (Moffet et al., 2010a) the following aerosol components: organic dominant, inorganic dominant, soot, potassium and carbonate. Such maps are shown for periods having low (T0, 27 June, 12:27) and high (T1, 28 June, 16:18) organic mass loadings as indicated by results from the bulk Sunset OCEC measurements (see Fig. 3).

Size distributions at T0 and T1 show that coarse-mode particles contribute significantly to the aerosol volume concentration (Kassianov et al., 2012). Previous source apportionment studies suggest that coarse-mode particles in the valley are dominated by sea salt with a smaller concentration from mineral dust (Chen et al., 2007). During periods of low organic aerosol, STXM maps indicate that many of the coarse-mode particles were dominated by inorganic species, 
07:00 PDT


12:00 PDT
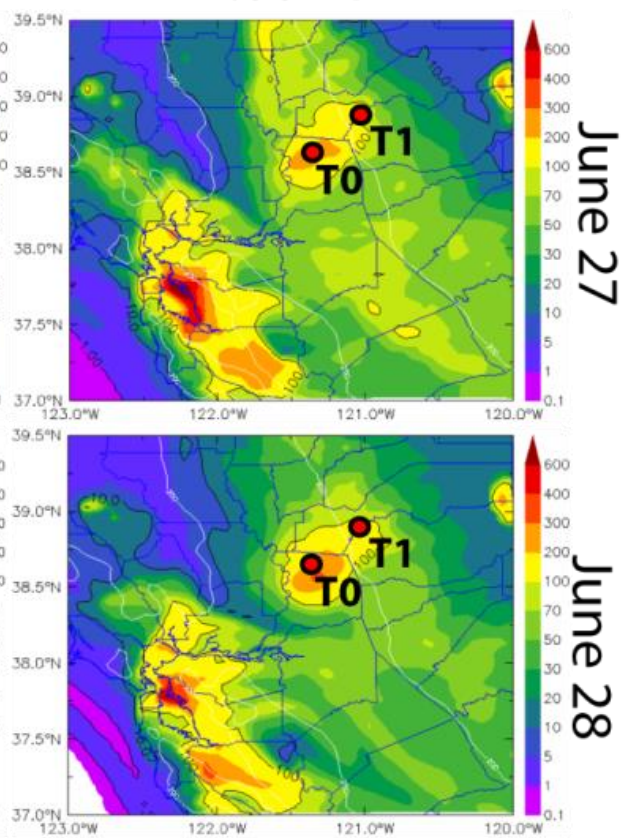

Fig. 2. Ensemble tracer maps for the Bay Area and Sacramento urban areas for 27-28 June 2010.

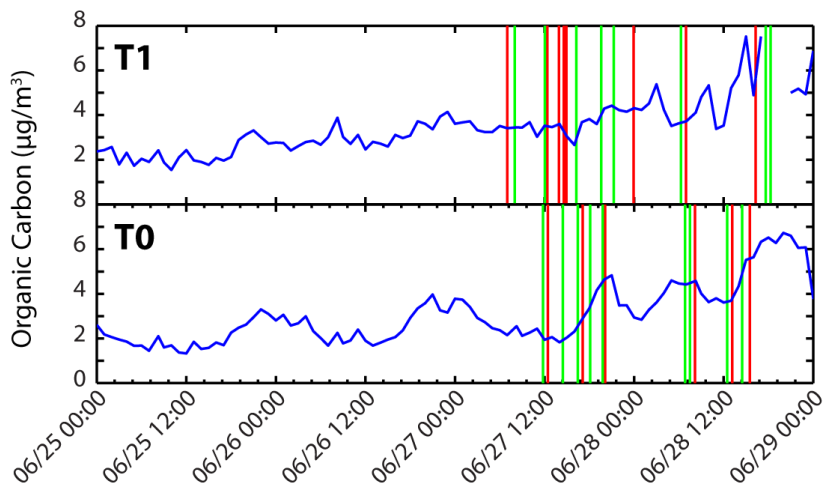

Fig. 3. Organic carbon mass concentrations for particles smaller than $2.5 \mu \mathrm{m}$ diameter as determined with the Sunset OCEC analyzer. Times for samples selected for STXM/NEXAFS analysis (red vertical lines) and for CCSEM/EDX analysis (green vertical lines) are indicated in the figure.

including $\mathrm{CO}_{3}$ and $\mathrm{K}$. Typically, large particles containing $\mathrm{CO}_{3}$ are either dust or sea salt (Laskin et al., 2012; Chen et al., 2007). Rectangular crystals, most likely sulfate, are frequently observed in inorganic dominant portions of individual particles. The STXM map for T0 on 27 June at 12:27 indicates that soot was also identified in some of the coarsemode particles. The smaller particles sampled on the afternoon of 27 June have potassium cores, which may be indicative of biomass or cooking sources. Small particles with potassium cores are coated by organics (green), indicating

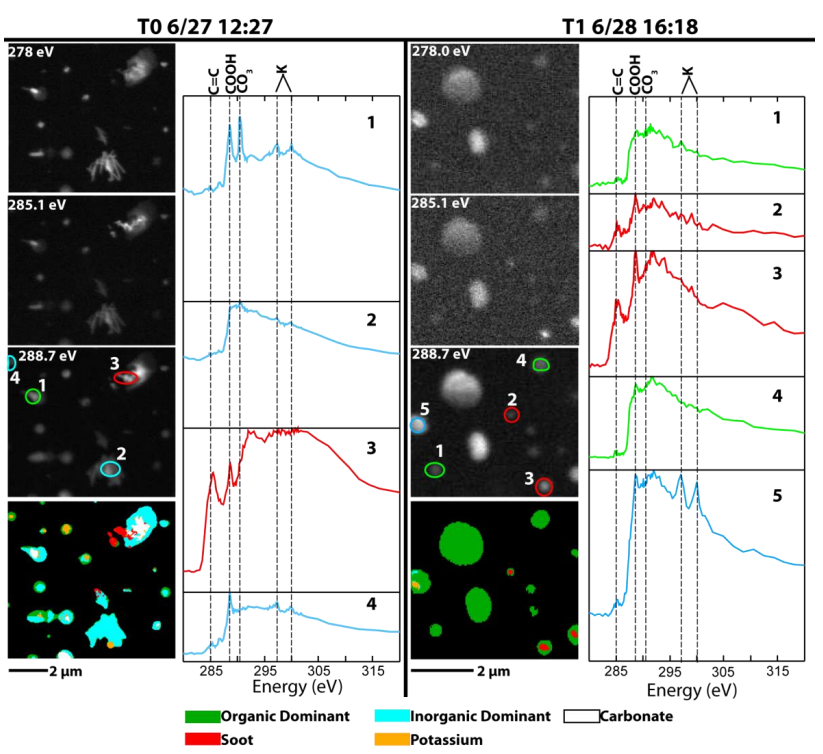

Fig. 4. Samples selected from a period of low (T0, 27 June, 12:27) and high (T1, 28 June, 16:18) organic mass loading displayed significant differences in mixing state. Single energy STXM/NEXAFS images and spectra show spatial distributions of major components identified at the carbon K-edge. Particles or regions where the spectra are obtained are indicated by numbers.

condensation of secondary organic aerosol onto the cores. Large fires likely had a negligible contribution to fine-mode potassium particles observed in this study (Fast et al., 2012). 
During a period of high organic aerosol loading at T1 (28 June, 16:18), particles examined with STXM/NEXAFS were primarily composed of homogeneous organic material. These particles were morphologically similar to secondary organic aerosol particles observed in Mexico City (Moffet et al., 2010b). The homogenous organic chemical composition indicates most of the organic mass was associated with particles that grew from organic cores smaller than $\sim 80 \mathrm{~nm}$. Small inorganic inclusions (including $\mathrm{K}$ ) and soot are occasionally seen in the center of organic particles. Particularly notable is the thick organic coating on particles containing soot (red) cores. The significant organic coating is consistent with the high photochemical activity and pollution buildup during this time period. Small potassium inclusions may indicate that some of the particles had primary cores possibly resulting from biomass or cooking sources.

Figure 5 shows representative SEM images of particles collected during periods of high (T0, 27 June, 12:27) and low (T1, 28 June, 17:38) organic aerosol loadings. Qualitatively, the observed trends are consistent with the STXM/NEXAFS data in Fig. 4. The sample from the time of low organic loadings displayed a variety of inorganic particles. Needlelike or compact crystals indicating sulfates and sea salt were frequently observed. Some of the inorganic species were internally mixed with soot. Minimal organic coatings were observed on the inorganic crystalline particles and almost no particles displayed a dominant organic composition. The sample from the time period of high organic loading displayed many oily-like particles that were predominantly composed of carbon. Within many of these oilylike particles, soot and crystalline inorganic inclusions were observed. The observations of these particle types in the organic-rich sample are consistent with the STXM/NEXAFS images shown in Fig. 4.

A morphologically unique class of biological particles was identified using SEM as shown in the bottom panel of Fig. 5. These particles, known as brochosomes, are commonly observed around the world and come from the integument of leaf hoppers (grasshoppers) (Wittmaack, 2005). Brochosomes were commonly observed at the T0 site, although exact number fractions could not be estimated using the current CCSEM/EDX or STXM/NEXAFS analysis protocols.

\subsection{CCSEM/EDX particle-type classification and aging trends}

Single-particle EDX spectra and the K-means clustering algorithm were used to group (cluster) the particles collected at T0 and T1 (Figs. 6 and 7) by elemental composition. The detailed characteristics of the coarse- (Fig. 6, brown shades) and fine-mode (Fig. 6, green shades) clusters are described in detail in the following sections.
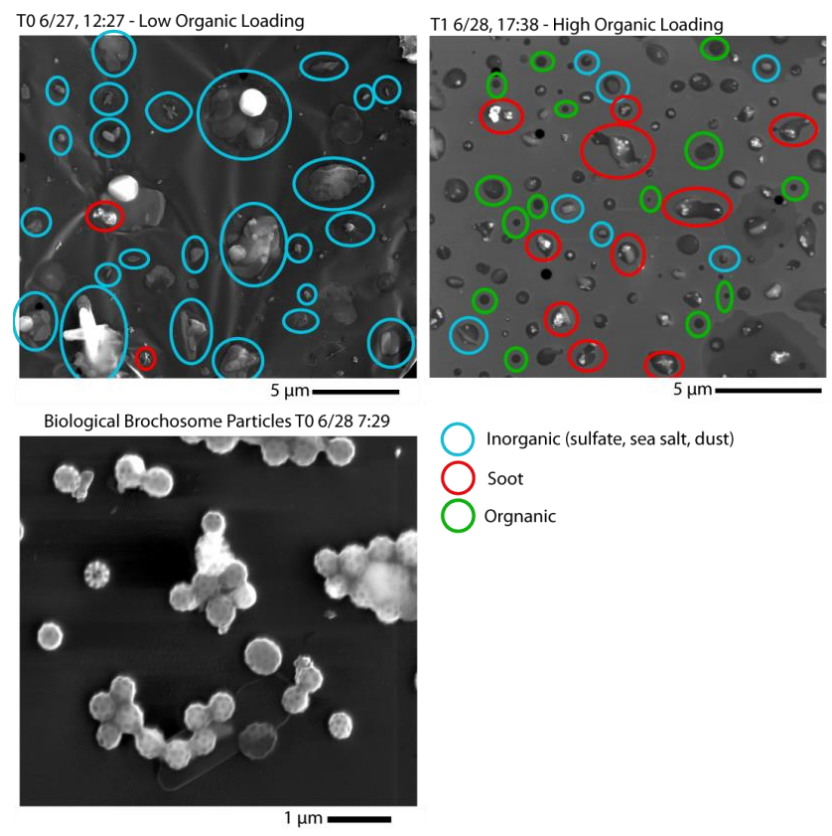

Orgnanic

Fig. 5. (Top) Representative SEM images of particles sampled at T0 and T1 during periods of low (T0, 27 June, 12:27) and high (T1, 28 June, 14:29) organic aerosol loading. (Bottom) An image of biological (brochosome) particles commonly observed during the CARES study.

\subsubsection{Fine-mode $(<1 \mu \mathrm{m})$ clusters}

Cluster 1 - nitrogen-containing carbonaceous. This finemode cluster represents the majority of the particles sampled. $\mathrm{N}, \mathrm{O}$, and $\mathrm{S}$ concentrations are above $1 \%$. This cluster has the most substantial enrichment in $\mathrm{N}$ compared to the other fine-mode clusters, most likely due to the presence of secondary nitrate. The trace presence of $\mathrm{Na}, \mathrm{Si}, \mathrm{Cl}$, and $\mathrm{K}$ may indicate an influence from dust and sea salt.

Cluster 4-secondary carbonaceous is characterized by a dominant contribution from carbon. The second most abundant element is $\mathrm{O}$, followed by $\mathrm{N}$ and $\mathrm{S}$. Compared to the other fine-mode clusters, this cluster has much less influence from elements other than $\mathrm{O}$. This cluster is labeled "secondary" due to the lack of trace elements that typically indicate a primary "core" containing non-volatile elements.

Cluster 6 - refractory carbonaceous has an enhanced contribution from refractory (nonvolatile) elements $\mathrm{Na}, \mathrm{Mg}, \mathrm{Ca}$, $\mathrm{Fe}, \mathrm{K}$, and $\mathrm{Cl}$ in addition to large contributions from $\mathrm{C}, \mathrm{N}$ and $\mathrm{O}$. These particles could be mixtures of sea salt or cooking emissions that have been coated with secondary organic species. This cluster is more abundant at the T0 site than the T1 site (Fig. 6c).

\subsubsection{Coarse-mode $(>1 \mu \mathrm{m})$ clusters}

Cluster 2 - coarse carbonaceous/nitrogenous contains many of the characteristics of the refractory carbonaceous class 6 


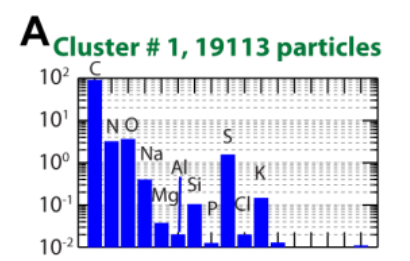

Cluster \# 3, 4484 particles

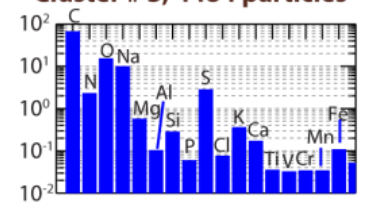

Cluster \# 5, 1620 particles

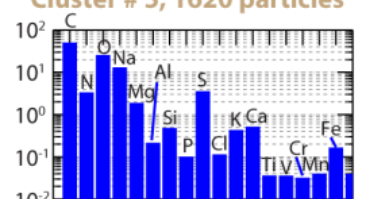

$10^{-2}$

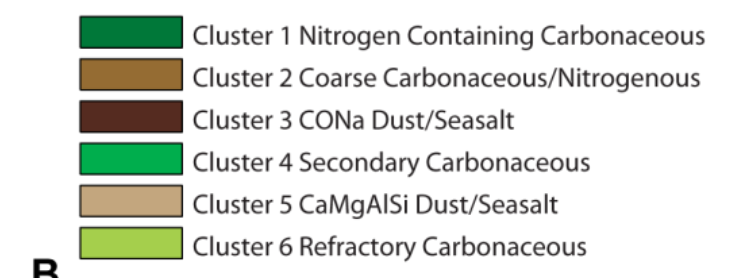

B

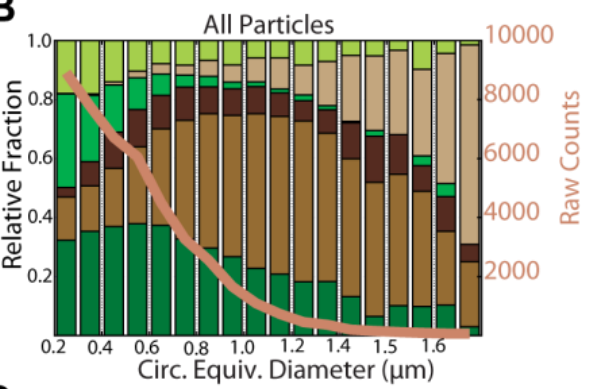

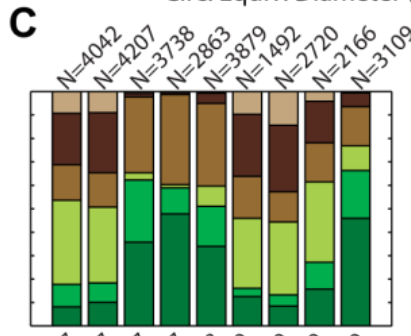

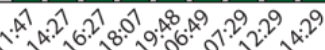

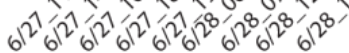

TO
Cluster \# 4, 13051 particles ${ }_{10}^{10^{2}}$ 年/ Cluster \# 6, 7117 particles

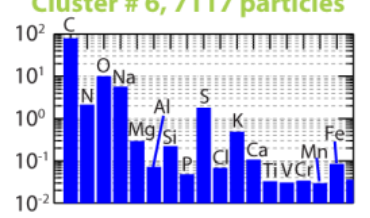

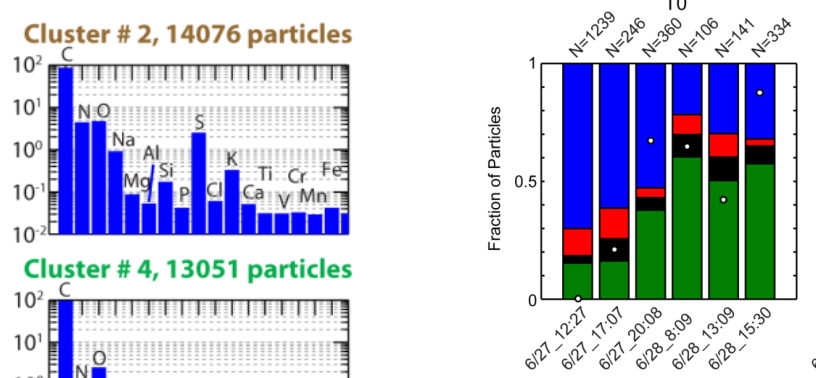

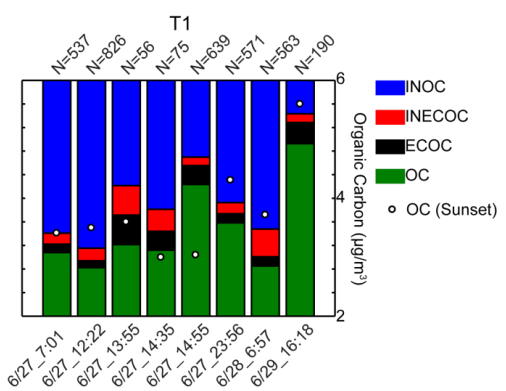

Fig. 7. Fractions of STXM-derived particle types for different sites (T0 and T1), dates, and times. White dots show organic carbon mass concentration determined by the Sunset OCEC analyzer.

with the exception of enhanced nitrogen content and larger particle size. As with cluster 6, cluster 2 contains small amounts of refractory elements, including $\mathrm{Na}, \mathrm{Si}$ and $\mathrm{K}$ indicating possible contributions from dust and sea salt in addition to secondary materials such as nitrates and secondary organic carbon.

Cluster 3 - CONa dust/sea salt has enhanced O content relative to the fine-mode clusters. Additionally, this cluster contains refractory elements typical of sea salt and dust.

Cluster 5 - CaMgAlSi dust/sea salt is similar to cluster 3 except for the enhancement in $\mathrm{Mg}, \mathrm{Si}, \mathrm{Al}$, and $\mathrm{Ca}$. The enhancement of $\mathrm{Si}, \mathrm{Al}$, and $\mathrm{Ca}$ suggests this cluster has more of a mineral dust influence.

\subsubsection{Size dependence of CCSEM/EDX clusters}

Average EDX spectra for the K-means clusters (Fig. 6a) show that all of the clusters (coarse and fine) contained substantial amounts of $\mathrm{C}, \mathrm{N}, \mathrm{O}, \mathrm{S}$, and Na. Most of the fine-mode clusters showed a strong enrichment in carbon compared to the coarse-mode clusters (Fig. 6a and b). Coarse-mode particles were typically enriched in $\mathrm{O}$ and $\mathrm{Na}$, as well as some enhancement in trace elements such as $\mathrm{Ca}, \mathrm{Fe}, \mathrm{Cl}, \mathrm{Si}, \mathrm{Al}$, and $\mathrm{Mg}$. Cluster 5 clearly contains more coarse-mode particles than cluster 3 and also contains an enhanced signal for crustal elements ( $\mathrm{Al}, \mathrm{Si}, \mathrm{Fe})$. The presence of $\mathrm{Na}$ indicates a sea salt influence. $\mathrm{K}$ is a common trace element in both the coarse and fine modes. In the fine mode, $\mathrm{K}$ is indicative of biomass or cooking, whereas in the coarse mode $\mathrm{K}$ is likely indicative of mineral dust and sea salt. Particles at T1 are slightly larger than particles at T0 (Fig. S1). At T1 this increase in particle size may be due to condensational growth of particles as they are transported from $\mathrm{T} 0$ to $\mathrm{T} 1$. Furthermore, cluster 1 is one of the most abundant fine-mode clusters at $\mathrm{T} 0$, whereas at $\mathrm{T} 1$ cluster 4 is the most abundant fine-mode cluster. The main differences between clusters 1 and 4 appear to be the fractional amount of carbon with respect to other elements (mainly S, N, O, K, and Na). This further supports the hypothesis that the organics present on particles increase upon transport from $\mathrm{T} 0$ to $\mathrm{T} 1$. 


\subsubsection{Temporal and geographic trends of CCSEM/EDX clusters}

Figure 6c displays clear differences in the cluster fractions at both T0 and T1 for all of the sampling times selected. The T0 sampling site contains more fine-mode carbonaceous particles containing refractory elements (cluster 6) compared to T1. At the urban source site, the presence of refractory elements in fine-mode particles is expected based on previous observations from Mexico City (Moffet et al., 2010b) and may be due to cooking and other residential/industrial combustion activities (Chen et al., 2007) that emit primary particles. Conversely, T1 contains more of the fine-mode OC "fresh" particles (cluster 4), possibly due to the growth of secondary organic aerosol (SOA) in the absence of primary cores supplied by the urban area. Moreover, while there is a relatively constant contribution of nitrogen containing carbonaceous particles (cluster 1) at $\mathrm{T} 1$, at $\mathrm{T} 0$ this particle class tends to grow in the late afternoons.

At both sites, the fine-mode carbonaceous classes (green shades, Fig. 6) are the most abundant in the afternoons when secondary organic aerosol formation is expected. At T0 during the entire time period from the 27th to the 28th the organic particle classes undergo a diurnal variation and show characteristic buildup to the highest contribution by the evening of the 28th. At T1 the buildup trend is less noticeable as the highest carbonaceous contribution is roughly equivalent with the value from the 27th. This is consistent with observations with STXM/NEXAFS, which are described below.

The number fraction of soot particles was slightly lower at $\mathrm{T} 1$, where $13.4 \%$ of particles contained soot inclusions, compared to $\mathrm{T} 0$, where $15.7 \%$ of the particles had soot inclusions. In Mexico City, the overall number fractions of sootcontaining particles was larger with $47.3,21.3$ and $16.6 \%$ of the particles containing soot inclusions at T0, T1, and T2, respectively. The number fraction of soot particles decreases due to a higher abundance of other particle types - particularly the OC particles.

\subsection{STXM/NEXAFS particle classification}

\subsubsection{Definition of mixing states based on STXM/NEXAFS}

Component maps produced by STXM/NEXAFS (Fig. 4) were used to classify internally mixed particles for a statistical analysis of mixing state trends over the pollution buildup period. Figure 7 illustrates the relative fraction of the different mixing states at $\mathrm{T} 0$ and $\mathrm{T} 1$. Figure $\mathrm{S} 2$ shows the STXM/NEXAFS-derived mixing state as a function of size. To improve particle statistics, after characterizing full spectra from numerous stacks, additional data are acquired at a few selected energies. Maps are then derived by the four images at 278, 285, 288 and $320 \mathrm{eV}$. For this dataset, 73 full stacks and 151 maps were acquired. The four mixing states described below were identified in a manner consistent with the previously published method of determining mixing state from STXM/NEXAFS data (Moffet et al., 2010a), with some minor changes to accommodate the four energy image maps. The identical algorithm was used to analyze both stacks and maps. The size limit for determining various regions within the particles was a spherical equivalent diameter of $\sim 50 \mathrm{~nm}$ depending on the spatial resolution used.

Organic Carbon (OC): OC particles have a dominant organic composition by mass homogeneously distributed throughout the entire particle. This is determined by comparing the pre-edge (an indicator of inorganic species such as sulfate) to the post-edge (proportional to total carbon) as detailed in Moffet et al. (2010a).

ECOC: regions of these particles have high $\mathrm{C}=\mathrm{C}$ aromatic $\mathrm{sp}^{2}$ hybridized carbon along with organic functional groups. The percentage of aromatic $\mathrm{sp}^{2}$ hybridized carbon bonds required for a particle to be designated with an EC component is greater than $35 \%$ (Hopkins et al., 2007).

INOC: these particles have an inorganic inclusion in addition to organic material. As shown in Moffet et al. (2010a) the ratio of pre-edge to post-edge will typically be greater than 0.5 when the mass of inorganic material is greater than that of the organic material. Hence, a ratio of 0.5 was selected to indicate inorganic inclusions.

INECOC: particles having inorganic dominant regions, soot regions, and organic regions are grouped in this class. The inorganic and soot inclusions are identified in a manner consistent with method used for the particle classes above.

It is somewhat challenging to make straightforward correlations between STXM and CCSEM classified particles because the two techniques are sensitive to different chemical species. However, there is some correspondence between the STXM mixing states and the clusters derived from CCSEM/EDX (Sect. 3.3). Typically, particles with "IN" phase detected by STXM have inclusions of non-carbonaceous material that are more abundant (by mass) than the organic phase. Therefore, many of the INOC particles consist of dust and sea salt, which correspond to clusters 1 and 4 due to the slightly lower sulfur content. Lastly, the particles identified as EC by STXM probably also belong to SEM clusters 1 and 4 due to their high carbon content. EDX spectroscopy cannot be used to identify soot because it is only sensitive to elemental composition, whereas STXM can readily be used to identify soot based on the characteristic NEXAFS features of $\mathrm{C}=\mathrm{Csp}{ }^{2}$ content. To illustrate these observations, the carbon-rich organic clusters were colored green in Fig. 6, indicating the OC STXM class shown in Fig. 7. The refractory carbonaceous SEM cluster (cluster 6), abundantly present at $\mathrm{T} 0$, is less abundant at T1, most likely due to a larger contribution from carbon compared to refractory elements $(\mathrm{Na}, \mathrm{K}$, $\mathrm{Fe})$. 


\subsubsection{Temporal trend in STXM/NEXAFS particle mixing states}

Figure 7 shows that the number fraction of organic particles without soot or inorganic inclusions increases with increasing organic aerosol mass concentration. Such behavior was observed in Mexico City and attributed to the growth of small particles by the condensation of low vapor pressure organics formed by gas phase oxidation reactions or by coagulation of small organic particles. For the current study, the same mechanism is expected; however, it is influenced by different meteorology. During the daytime, upslope flow carries oxidants, OA, and SOA precursors from the greater Sacramento area to T1, where it mixes with biogenic VOCs from both anthropogenic and biogenic sources (Steiner et al., 2008). Continued oxidation occurs at the $\mathrm{T} 1$ site during the daytime, after which the air mass is transported by downslope flow towards Sacramento and is more enriched in organic aerosol than it was in the morning. This process partially explains why the organic carbon concentration at $\mathrm{T} 0$ on 28 June is higher than the organic mass concentration at T0 on 27 June.

The upslope/downslope phenomenon can also explain the variability in mixing states observed at T1. At T1, the relative fraction of organic dominant particles without inclusions is the highest in the late afternoon when the boundary layer over the Central Valley was above the level of the T1 site. These OC particles are most likely secondary organic aerosols. As downslope winds begin in the evening to early morning hours, particles with inorganic inclusions start to dominate at T1. It is possible that these particles were entrained from the free troposphere. It has been observed in previous studies in the Sierra Nevada that the nighttime downslope flow causes air from the free troposphere to be mixed towards the ground in the early morning hours (Murphy et al., 2006).

\subsection{Transformation of total carbon and carbon speciation with age}

As the urban plume ages, the contribution from secondary organic aerosol is expected to increase (Jimenez et al., 2009). Oxidation of gas phase organic species leads to both nucleation and condensation on to pre-existing aerosol particles. Figure 8 shows the total organic carbon contained in individual particles as a function of size and time for T0 and T1. Organic carbon was derived by the STXM measurements by excluding inorganic carbon (soot, carbonate when applicable) from the quantification of optical density for individual particles. Figure 8 shows that as the aerosol plume aged, the total organic carbon increased on all particles across the size distribution, indicating condensation of organic material onto particles. As particle size increases, the total organic carbon within the particles increases as well. Particles larger than $1 \mu \mathrm{m}$ are typically generated mechanically, so the fact that organic carbon increases on these particles indicates
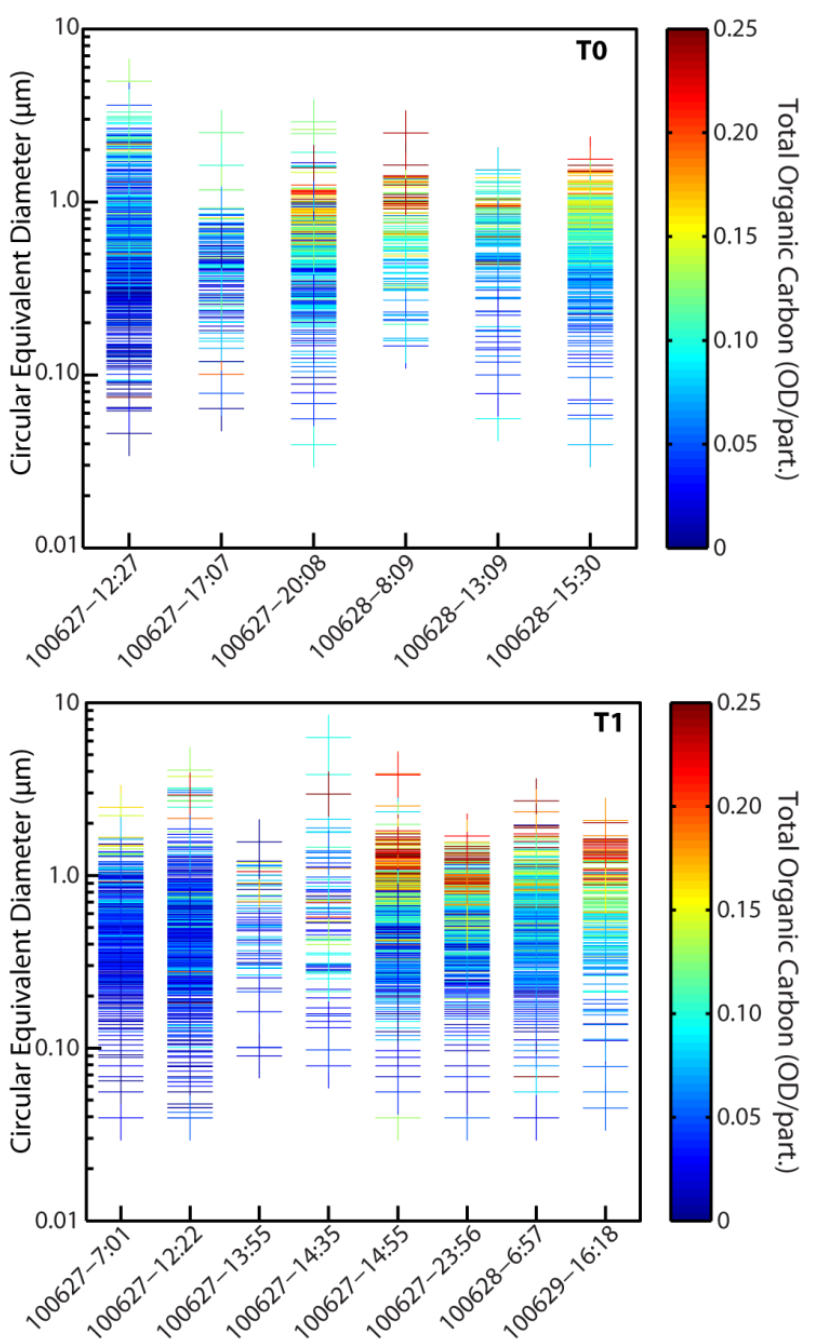

Fig. 8. Size and total organic carbon (color scale) for individual particles (represented as crosses) for the different sampling times at T0 (top) and T1 (bottom). Organic carbon was determined by masking elemental carbon inclusions and averaging over the total carbon remaining in individual particles.

condensation of secondary organic species on primary particles. The increase in organic carbon at smaller sizes may be due to either growth of primarily organic particles or condensation of organics on inorganic seeds. However, the observation that the population of particles without inclusions increases over all sizes (both sub- and supermicron; see Figs. S1 and S2) indicates that growth of nucleation mode organic particles via condensation or coagulation is responsible for the overall increase in organic material. SEM cluster 1 (nitrogen-rich organic) and the STXM OC class are present in the highest abundance at small sizes (Figs. S1 and S2). As the plume ages, these particle classes increase with size in a similar fashion to what was observed in Mexico City.

Submicron size distributions show that nucleation events are frequent at both the T0 and T1 sites (Mei et al., 2013; 

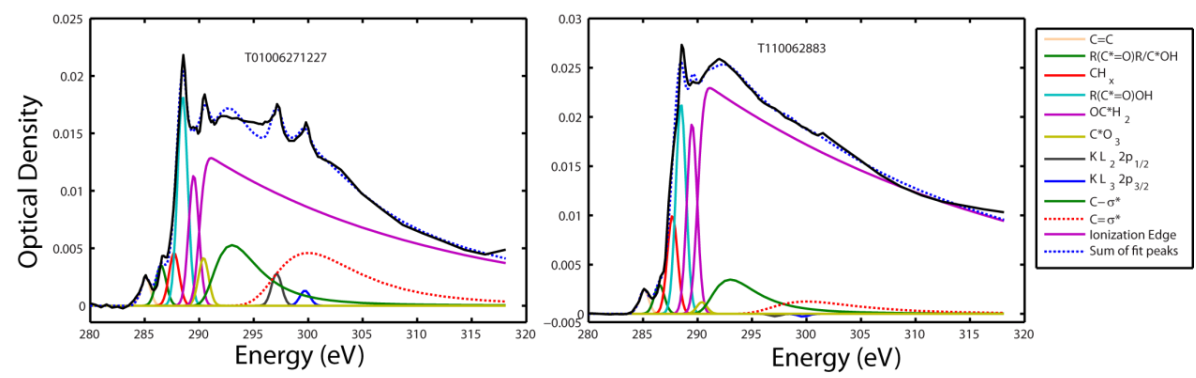

Fig. 9. Average NEXAFS spectra (black solid line) obtained from T0 on 27 June 2011, 12:27 LST (left) and T1 on 28 June 2011, 16:18 LST (right). Peaks from various transitions are indicated by colored solid lines.

Setyan et al., 2012; Zaveri et al., 2012). From these observations, it is clear that nucleation mode particles contribute to the overall aerosol population on a daily basis. At T0, nucleation events were initiated daily at sunrise, while at T1 the events seemed to happen later in the afternoon (around 12 p.m. local time). How much of a contribution these atmospherically nucleated organic particles make to the accumulation mode population via condensation and coagulation can be estimated using a modeling study with accurate emissions. It is expected that the homogeneous organic dominant particles are due to condensational growth of nucleation mode particles or coagulation of organic-rich nucleation mode particles with each other. Particles with ammonium sulfate cores would likely be identified as INOC, so these inorganic/organic mixed particles could be isolated in a model as long as the source and phase of ammonium sulfate is adequately represented.

Comparison of particles collected in Mexico City with those collected in Sacramento is useful to gain insight into how the conditions in different environments affect the characteristics of individual particles. To compare the amount of organic carbon on the particles, number concentrations during the two field studies need to be considered. The size distributions measured with STXM were similar for both MILAGRO and CARES. Absolute number concentrations during CARES peaked at roughly 30000 particles $\mathrm{cm}^{-3}$ at T0 and 10000 part particles $\mathrm{cm}^{-3}$ at $\mathrm{T} 1$ (Zaveri et al., 2012). In Mexico City, total particle concentrations peaked at roughly 50000 particles $\mathrm{cm}^{-3}$ (Kleinman, 2009). Therefore, since the number concentrations in Mexico City are higher, it is expected that there would be less condensed organic mass per particle. However, height of the boundary layer can also affect gas-particle partitioning. MILAGRO boundary layer was at $500 \mathrm{~m}$ at sunrise (06:40 LST) and rose to $3000 \mathrm{~m}$ at approximately 15:00 LST (Doran et al., 2007; Shaw et al., 2007). The situation at T0 and T1 during CARES was somewhat different due to the elevation difference between T0 and T1. Nevertheless, the boundary layer heights were below $500 \mathrm{~m}$ at sunrise and rose as high as $2000 \mathrm{~m}$ in the evening (Fast et al., 2012).
To compare the characteristics of organic carbon (regions of particles with soot particles are not considered here) obtained using STXM measurements from the CARES and Mexico City MILAGRO campaign, a deconvolution analysis of average NEXAFS spectra was performed. Figure 9 shows representative results of the deconvolution analysis from $\mathrm{T} 0$ and T1 during CARES. The sampling times chosen in Fig. 9 represent fresh (T0, 27 June 2011, 12:27 LST) and aged (T1, 28 June 2011, 16:18 LST) time periods. The higher absorption at the carbon post-edge $(320 \mathrm{eV}$, proportional to total carbon) indicates the increase in organic carbon due to secondary aerosol formation. Furthermore, peaks from $\mathrm{CO}_{3}$ and potassium further demonstrate the influence from refractory material such as mineral dust, sea salt and biomass to extensive secondary organic aerosol formation. The observation of more refractory material at the T0 site is consistent with the CCSEM/EDX data discussed in Sect. 3.3. The NEXAFS spectra are qualitatively similar to those obtained from Mexico City, thus indicating comparable contributions of organic functional groups. Furthermore, fresh primary emissions in Mexico City also showed enhanced potassium and carbonate signatures in the NEXAFS spectra (Moffet et al., 2010b).

Figure 10 shows integrated total carbon per particle for a series of samples from $\mathrm{T} 0$ and $\mathrm{T} 1$ between 27 June and 28 June. Generally, the trend of increasing total organic carbon is expected given the observations in the previous discussion. Fresh particles during CARES had organic carbon contents of $\sim 1 \mathrm{OD} * \mathrm{eV} /$ particle, and aged particles during CARES had a maximum organic carbon content of $\sim 5 \mathrm{OD} * \mathrm{eV} /$ particle. Fresh particles from Mexico City contained three times more organic carbon $(\sim 3 \mathrm{OD} * \mathrm{eV} /$ particle $)$ than the fresh particles from CARES. Aged particles from Mexico City had a maximum organic carbon content of $7 \mathrm{OD} * \mathrm{eV} /$ particle. The analyzed size distributions from MILAGRO and CARES were similar. These measurements indicate that the increased carbon content of the fresh particles sampled during MILAGRO may be the result of a denser organic phase, thicker particles (on the substrate) or a combination of both. The larger organic content of the Mexico City particles compared to Sacramento particles is reasonable considering the more intense photochemistry in Mexico 


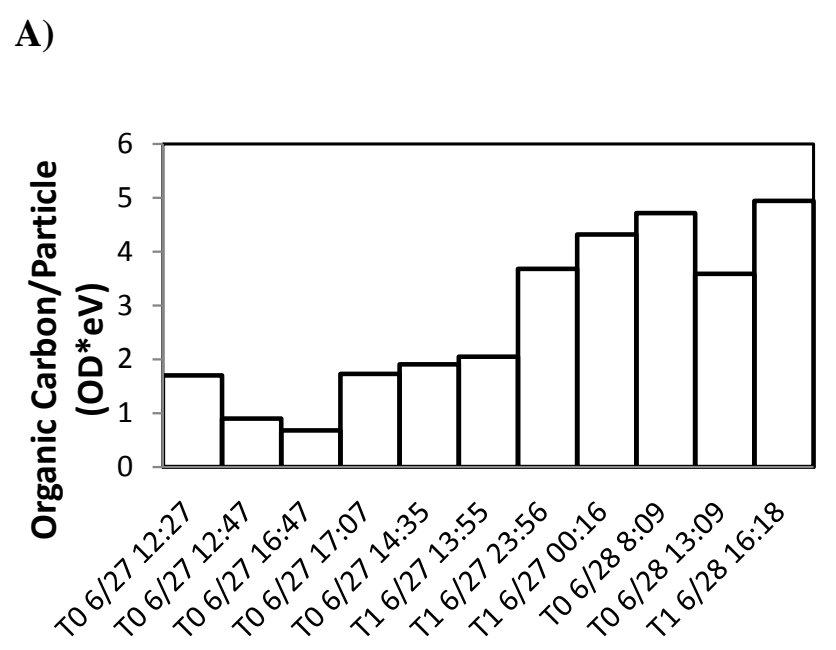

B)

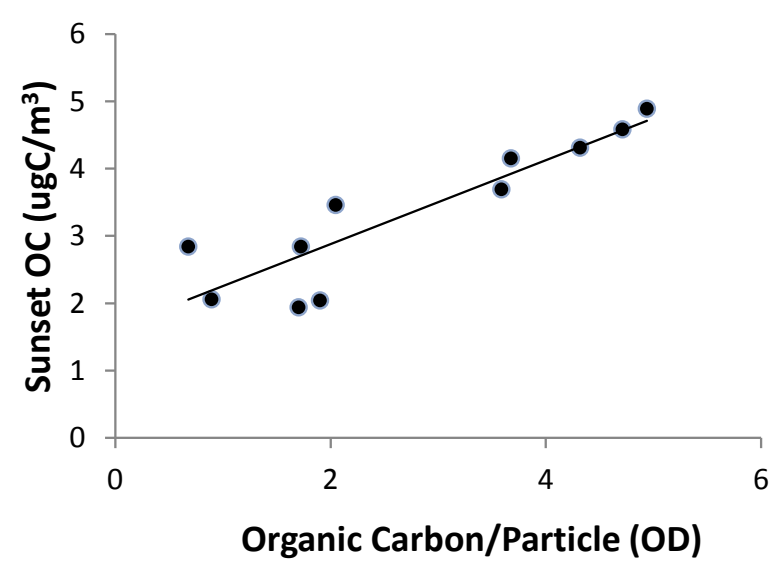

Fig. 10. (A) Trend in average total organic carbon per particle determined by integrating the ionization edge step. (B) Relationship between organic carbon optical density per particle and bulk organic mass concentration measured by Sunset OCEC analyzer.

City (Molina et al., 2010; Molina and Molina, 2002). For the CARES field study, the low organic carbon observed for the fresh particles at T0 may be explained by a stronger source of submicron inorganic particles such as sulfates from the Carquinez Strait and sea spray particles from the Pacific Ocean.

Insight into how organic carbon is mixed over all particles can be elucidated by comparing to bulk measurements of organic carbon mass. Figure 10b shows the relationship between total organic carbon per particle determined by STXM and the bulk organic carbon mass concentration determined by the Sunset OCEC field analyzer at the corresponding TRAC sampling times. The relationship between bulk carbon mass concentrations and single-particle carbon concentrations is linear. As the carbon mass concentration increases, the strength of correlation increases. The larger degree of scatter at low organic carbon concentrations may be due

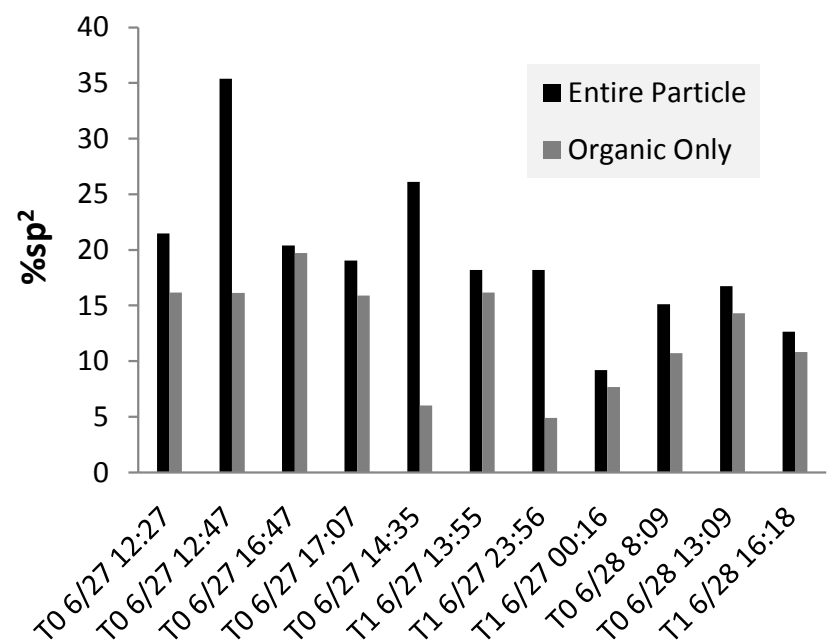

Fig. 11. Percentage of aromatic $\mathrm{sp}^{2}$ hybridized carbon for whole particles and organic regions of particles during CARES.

to different externally mixed inorganic and organic particle populations. The overall linearity of Figure 10b indicates internal mixing of organic carbon across particle classes. This analysis was carried out for the Mexico City dataset; however, OCEC measurements were not available for T0 and the number of particles concentration was much lower. Although the correlation was positive, it was not as strong $\left(R^{2}=0.03\right)$.

NEXAFS measurements showed the presence of aromatic $\mathrm{sp}^{2}$ hybridized carbon $\mathrm{C}=\mathrm{C}$ bonds in organic aerosols at both T0 and T1 sites. Organic aerosols containing $\mathrm{C}=\mathrm{C}$ bonds have been previously observed in other field studies (Moffet et al., 2010b; Zaveri et al., 2010; Takahama et al., 2007). $\mathrm{C}=\mathrm{C}$ bonds in primary organic aerosols can arise from polycyclic aromatic hydrocarbons present in vehicular exhaust. Secondary production of $\mathrm{C}=\mathrm{C}$ bonds has also been suggested (Noziere et al., 2007). Previous field observations have found the percentage of $\mathrm{C}=\mathrm{C}$ bonds to decrease with plume age (Moffet et al., 2010b), suggesting that the rate of destruction exceeds the rate of formation. Carboncarbon double bonds are reactive to oxidants such as $\mathrm{OH}$ and $\mathrm{NO}_{3}$ radicals and ozone. As the organic material is oxidized, the fraction of organic carbon double bonds (normalized to total carbon) is expected to decrease. The percentage of aromatic $\mathrm{sp}^{2}$ hybridized carbon (" $\% \mathrm{sp}^{2}$ ") for the T0 and $\mathrm{T} 1$ sites is shown in Fig. 11. The values of $\% \mathrm{sp}^{2}$ are shown for entire particles and for only organic regions that have had the soot contribution to $\% \mathrm{sp}^{2}$ masked. The lowest values of $\% \mathrm{sp}^{2}$ were observed at the end of the study period when the most aged aerosol dominated. These results are similar to those obtained in Mexico City; however, for the most aged samples, the amount of aromatic $\mathrm{sp}^{2}$ hybridized carbon atoms observed during the CARES study is lower. For organic carbon, the lowest value of $\% \mathrm{sp}^{2}$ during CARES was $4.9 \pm 0.3 \%$, whereas during MILAGRO the lowest value was $13.0 \pm 0.2 \%$. The percentage of aromatic $\mathrm{sp}^{2}$ carbon atoms 
in aged samples from Sacramento compared to Mexico City may arise due to different secondary organic aerosol precursors and chemistry. Alternatively, it is possible that vehicular emissions in Mexico City contain more polycyclic aromatic hydrocarbons compared to the organic aerosol precursors present during the CARES study.

\section{Conclusions}

Between 27 June and 29 June 2010 of the CARES study, meteorological conditions led to the accumulation of gas and aerosol phase pollutants within a regionally stagnant air mass. Carbon monoxide tracer forecasts indicate that the urban plume originating at T0 was effectively transported to $\mathrm{T} 1$ during this time. These plume characteristics allowed for spectro-microscopic measurements of carbonaceous aerosol aging at the T0 urban site and the T1 rural site. Based on CCSEM/EDX and STXM/NEXAFS measurements, the characteristics of particles containing organic carbon changed in the following ways:

1. The amount of carbon per particle increased as a function of plume age. Carbon-rich classes determined by the CCSEM/EDX were most abundant at the $\mathrm{T} 1$ site.

2. CCSEM/EDX identified the presence of elements (Na and $\mathrm{K}$ ) indicative of refractory species in both the coarse and fine mode. These refractory particle types were most abundant at the $\mathrm{T} 0$ urban site.

3. STXM/NEXAFS measurements indicate that the number fraction of organic particles that lack inorganic inclusions increased as a function of plume age. This indicates that organic mass increased by condensation and coagulation of small, organic dominant nucleation mode particles.

4. STXM/NEXAFS measurements show an increase in organic carbon on $0.20 \mu \mathrm{m}-2 \mu \mathrm{m}$ particles as a function of plume age. This observation is most likely the direct result of the condensation of organic compounds on the surface of the particles as aging occurs.

5. While the origin of the observed $\mathrm{C}=\mathrm{C}$ bonds is not clear, their percentage in organic aerosols decreased with plume age, possibly due to the occurrence of oxidation reactions.

Comparing these results from the CARES campaign to previous results obtained during the MILAGRO campaign, it was determined that fresh organic particles in Mexico City contain three times as much carbon by mass. This may be due to the differences in sources of inorganic particles at the two sites. Furthermore, particle phase organic matter in aged particles from Mexico City contained more double bonds than it did in California. The similarities and differences of the observations between the CARES and MILAGRO datasets provide reference with which to compare measurements with process models. These detailed spectro-microscopic measurements represent some of the most detailed observations available on the aging of organic aerosols. Such measurements are essential for developing an improved process-level understanding of aerosol formation and aging and their impacts on radiative and cloud nucleating properties.

\section{Supplementary material related to this article is available online at http://www.atmos-chem-phys.net/13/ 10445/2013/acp-13-10445-2013-supplement.pdf.}

Acknowledgements. This research was supported by the Office of Science (BER), US Department of Energy. Part of this work was supported by award number DE-SC0008643. The authors gratefully acknowledge the support of the Department of Energy's Atmospheric Systems Research (ASR) program. The CCSEM/EDX particle analysis was performed in the Environmental Molecular Sciences Laboratory, a national scientific user facility sponsored by OBER at Pacific Northwest National Laboratory. PNNL is operated by the U.S. Department of Energy by Battelle Memorial Institute under contract DE-AC06-76RL0. The STXM/NEXAFS particle analysis was performed at beamlines 11.0.2 and 5.3.2 at the Advanced Light Source at Lawrence Berkeley National Laboratory. The work at the Advanced Light Source was supported by the Director, Office of Science, Office of Basic Energy Sciences, of the US Department of Energy under contract no. DE-AC02-05CH11231. We thank D. Kilcoyne and T. Tyliszczak for their tireless efforts in keeping the ALS STXM beamlines operational. R. C. Moffet thanks the QGIS community for making their mapping software freely available. QGIS and the USDA's national atlas were used in the production of Fig. 1.

Edited by: D. J. Cziczo

\section{References}

Ackerman, T. P. and Toon, O. B.: Absorption of Visible Radiation in Atmosphere Containing Mixtures of Absorbing and NonAbsorbing Particles, Appl. Optics, 20, 3661-3668, 1981.

Adachi, K. and Buseck, P. R.: Internally mixed soot, sulfates, and organic matter in aerosol particles from Mexico City, Atmos. Chem. Phys., 8, 6469-6481, doi:10.5194/acp-8-6469-2008, 2008.

Beaver, S., Palazoglu, A., Singh, A., Soong, S. T., and Tanrikulu, S.: Identification of weather patterns impacting 24-h average fine particulate matter pollution, Atmos. Environ., 44, 1761-1771, 2010.

Bouvier-Brown, N. C., Goldstein, A. H., Gilman, J. B., Kuster, W. C., and de Gouw, J. A.: In-situ ambient quantification of monoterpenes, sesquiterpenes, and related oxygenated compounds during BEARPEX 2007: implications for gas- and particle-phase chemistry, Atmos. Chem. Phys., 9, 5505-5518, doi:10.5194/acp-9-5505-2009, 2009. 
Cappa, C. D., Onasch, T. B., Massoli, P., Worsnop, D. R., Bates, T. S., Cross, E. S., Davidovits, P., Hakala, J., Hayden, K. L., Jobson, B. T., Kolesar, K. R., Lack, D. A., Lerner, B. M., Li, S. M., Mellon, D., Nuaaman, I., Olfert, J. S., Petaja, T., Quinn, P. K., Song, C., Subramanian, R., Williams, E. J., and Zaveri, R. A.: Radiative Absorption Enhancements Due to the Mixing State of Atmospheric Black Carbon, Science, 337, 1078-1081, doi:10.1126/science.1223447, 2012.

Chen, L. W. A., Watson, J. G., Chow, J. C., and Magliano, K. L.: Quantifying PM2.5 source contributions for the San Joaquin Valley with multivariate receptor models, Environ. Sci. Technol., 41, 2818-2826, doi:10.1021/es0525105, 2007.

DeMott, P. J. and Prenni, A. J.: New Directions: Need for defining the numbers and sources of biological aerosols acting as ice nuclei, Atmos. Environ., 44, 1944-1945, 2010.

Doran, J. C., Barnard, J. C., Arnott, W. P., Cary, R., Coulter, R., Fast, J. D., Kassianov, E. I., Kleinman, L., Laulainen, N. S., Martin, T., Paredes-Miranda, G., Pekour, M. S., Shaw, W. J., Smith, D. F., Springston, S. R., and Yu, X.-Y.: The T1-T2 study: evolution of aerosol properties downwind of Mexico City, Atmos. Chem. Phys., 7, 1585-1598, doi:10.5194/acp-7-1585-2007, 2007.

Fast, J. D., Gustafson Jr., W. I., Berg, L. K., Shaw, W. J., Pekour, M., Shrivastava, M., Barnard, J. C., Ferrare, R. A., Hostetler, C. A., Hair, J. A., Erickson, M., Jobson, B. T., Flowers, B., Dubey, M. K., Springston, S., Pierce, R. B., Dolislager, L., Pederson, J., and Zaveri, R. A.: Transport and mixing patterns over Central California during the carbonaceous aerosol and radiative effects study (CARES), Atmos. Chem. Phys., 12, 1759-1783, doi:10.5194/acp-12-1759-2012, 2012.

Ghan, S. J. and Schwartz, S. E.: Aerosol properties and processes A path from field and laboratory measurements to global climate models, B. Am. Meteorol. Soc., 88, 1059-+, 2007.

Hadley, O. L., Corrigan, C. E., Kirchstetter, T. W., Cliff, S. S., and Ramanathan, V.: Measured black carbon deposition on the Sierra Nevada snow pack and implication for snow pack retreat, Atmos. Chem. Phys., 10, 7505-7513, doi:10.5194/acp-10-75052010, 2010.

Hansson, H. C., Rood, M. J., Koloutsou-Vakakis, S., Hameri, K., Orsini, D., and Wiedensohler, A.: $\mathrm{NaCl}$ aerosol particle hygroscopicity dependence on mixing with organic compounds, J. Atmos. Chem., 31, 321-346, 1998.

Harley, R. A., Marr, L. C., Lehner, J. K., and Giddings, S. N.: Changes in motor vehicle emissions on diurnal to decadal time scales and effects on atmospheric composition, Environ. Sci. Technol., 39, 5356-5362, 2005.

Hopkins, R. J., Tivanski, A. V., Marten, B. D., and Gilles, M. $\mathrm{K}$.: Chemical bonding and structure of black carbon reference materials and individual carbonaceous atmospheric aerosols, J. Aerosol Sci., 38, 573-591, doi:10.1016/j.jaerosci.2007.03.009, 2007.

IPCC: Climate Change 2007: The Physical Science Basis, Cambridge University Press, New York, 2007.

Jacobson, M. Z.: Strong radiative heating due to the mixing state of black carbon in atmospheric aerosols, Nature, 409, 695-697, 2001.

Jimenez, J. L., Canagaratna, M. R., Donahue, N. M., Prevot, A. S. H., Zhang, Q., Kroll, J. H., DeCarlo, P. F., Allan, J. D., Coe, H., Ng, N. L., Aiken, A. C., Docherty, K. S., Ulbrich, I. M., Grieshop, A. P., Robinson, A. L., Duplissy, J., Smith, J. D., Wil- son, K. R., Lanz, V. A., Hueglin, C., Sun, Y. L., Tian, J., Laaksonen, A., Raatikainen, T., Rautiainen, J., Vaattovaara, P., Ehn, M., Kulmala, M., Tomlinson, J. M., Collins, D. R., Cubison, M. J., Dunlea, E. J., Huffman, J. A., Onasch, T. B., Alfarra, M. R., Williams, P. I., Bower, K., Kondo, Y., Schneider, J., Drewnick, F., Borrmann, S., Weimer, S., Demerjian, K., Salcedo, D., Cottrell, L., Griffin, R., Takami, A., Miyoshi, T., Hatakeyama, S., Shimono, A., Sun, J. Y., Zhang, Y. M., Dzepina, K., Kimmel, J. R., Sueper, D., Jayne, J. T., Herndon, S. C., Trimborn, A. M., Williams, L. R., Wood, E. C., Middlebrook, A. M., Kolb, C. E., Baltensperger, U., and Worsnop, D. R.: Evolution of Organic Aerosols in the Atmosphere, Science, 326, 1525-1529, doi:10.1126/science.1180353, 2009.

Johnson, K. S., Zuberi, B., Molina, L. T., Molina, M. J., Iedema, M. J., Cowin, J. P., Gaspar, D. J., Wang, C., and Laskin, A.: Processing of soot in an urban environment: case study from the Mexico City Metropolitan Area, Atmos. Chem. Phys., 5, 3033-3043, doi:10.5194/acp-5-3033-2005, 2005.

Kassianov, E. I., Pekour, M., and Barnard, J.: Aerosols in central California: Unexpectedly large contribution of coarse mode to aerosol radiative forcing, Geophys. Res. Lett., 39, L20806, doi:10.1029/2012GL053469, 2012.

Kilcoyne, A. L. D., Tyliszczak, T., Steele, W. F., Fakra, S., Hitchcock, P., Franck, K., Anderson, E., Harteneck, B., Rightor, E. G., Mitchell, G. E., Hitchcock, A. P., Yang, L., Warwick, T., and Ade, H.: Interferometer-controlled scanning transmission X-ray microscopes at the Advanced Light Source, J. Synchrotron Radiat., 10, 125-136, 2003.

Kleinman, L. I., Springston, S. R., Wang, J., Daum, P. H., Lee, Y.-N., Nunnermacker, L. J., Senum, G. I., Weinstein-Lloyd, J., Alexander, M. L., Hubbe, J., Ortega, J., Zaveri, R. A., Canagaratna, M. R., and Jayne, J.: The time evolution of aerosol size distribution over the Mexico City plateau, Atmos. Chem. Phys., 9, 4261-4278, doi:10.5194/acp-9-4261-2009, 2009.

Knopf, D. A., Wang, B., Laskin, A., Moffet, R. C., and Gilles, M. K.: Heterogeneous nucleation of ice on anthropogenic organic particles collected in Mexico City, Geophys. Res. Lett., 37 L11803, doi:10.1029/2010g1043362, 2010.

Laskin, A., Iedema, M. J., and Cowin, J. P.: Time-resolved aerosol collector for CCSEM/EDX single-particle analysis, Aerosol Sci. Tech., 37, 246-260, 2003.

Laskin, A., Cowin, J. P., and Iedema, M. J.: Analysis of individual environmental particles using modern methods of electron microscopy and X-ray microanalysis, J. Electron Spectrosc., 150, 260-274, 2006.

Laskin, A., Moffet, R. C., Gilles, M. K., Fast, J. D., Zaveri, R. A., Wang, B. B., Nigge, P., and Shutthanandan, J.: Tropospheric chemistry of internally mixed sea salt and organic particles: Surprising reactivity of $\mathrm{NaCl}$ with weak organic acids, J. Geophys. Res.-Atmos., 117, D15302, doi:10.1029/2012jd017743, 2012.

Marr, L. C., Black, D. R., and Harley, R. A.: Formation of photochemical air pollution in central California - 1. Development of a revised motor vehicle emission inventory, J. Geophys. Res.Atmos., 107, ACH 5-1-ACH 5-9, doi:10.1029/2001JD000689, 2002a.

Marr, L. C., Noblet, G. S., and Harley, R. A.: Formation of photochemical air pollution in central California - 2. Impact of revised emissions on Eulerian model predictions, J. Geophys. Res.- 
Atmos., 107, ACH 6-1-ACH 6-11, doi:10.1029/2001JD000690, 2002b.

Mei, F., Setyan, A., Zhang, Q., and Wang, J.: CCN activity of organic aerosols observed downwind of urban emissions during CARES, Atmos. Chem. Phys. Discuss., 13, 9355-9399, doi:10.5194/acpd-13-9355-2013, 2013.

Meyer, N. K., Duplissy, J., Gysel, M., Metzger, A., Dommen, J., Weingartner, E., Alfarra, M. R., Prevot, A. S. H., Fletcher, C., Good, N., McFiggans, G., Jonsson, Å. M., Hallquist, M., Baltensperger, U., and Ristovski, Z. D.: Analysis of the hygroscopic and volatile properties of ammonium sulphate seeded and unseeded SOA particles, Atmos. Chem. Phys., 9, 721-732, doi:10.5194/acp-9-721-2009, 2009.

Moffet, R. C. and Prather, K. A.: In-situ measurements of the mixing state and optical properties of soot with implications for radiative forcing estimates, P. Natl. Acad. Sci. USA, 106, 1187211877, 2009.

Moffet, R. C., de Foy, B., Molina, L. T., Molina, M. J., and Prather, K. A.: Measurement of ambient aerosols in northern Mexico City by single particle mass spectrometry, Atmos. Chem. Phys., 8, 4499-4516, doi:10.5194/acp-8-4499-2008, 2008.

Moffet, R. C., Henn, T., Laskin, A., and Gilles, M. K.: Automated Chemical Analysis of Internally Mixed Aerosol Particles Using X-ray Spectromicroscopy at the Carbon K-Edge, Anal. Chem., 82, 7906-7914, 2010a.

Moffet, R. C., Henn, T. R., Tivanski, A. V., Hopkins, R. J., Desyaterik, Y., Kilcoyne, A. L. D., Tyliszczak, T., Fast, J., Barnard, J., Shutthanandan, V., Cliff, S. S., Perry, K. D., Laskin, A., and Gilles, M. K.: Microscopic characterization of carbonaceous aerosol particle aging in the outflow from Mexico City, Atmos. Chem. Phys., 10, 961-976, doi:10.5194/acp-10-961-2010, 2010b.

Moffet, R. C., Tivanski, A. V., and Gilles, M. K.: Scanning Transmission X-ray Microscopy, in: Fundamentals and Applications in Aerosol Spectroscopy, edited by: Signorell, R. and Reid, J. P., CRC Press, Boca Raton, 419-462, 2011.

Molina, M. J. and Molina, L. T.: Air Quality in the Mexico Megacity: An Integrated Assessment, Kluwer Academic, 2002.

Molina, L. T., Kolb, C. E., de Foy, B., Lamb, B. K., Brune, W. H., Jimenez, J. L., Ramos-Villegas, R., Sarmiento, J., ParamoFigueroa, V. H., Cardenas, B., Gutierrez-Avedoy, V., and Molina, M. J.: Air quality in North America's most populous city overview of the MCMA-2003 campaign, Atmos. Chem. Phys., 7, 2447-2473, doi:10.5194/acp-7-2447-2007, 2007.

Molina, L. T., Madronich, S., Gaffney, J. S., Apel, E., de Foy, B., Fast, J., Ferrare, R., Herndon, S., Jimenez, J. L., Lamb, B., Osornio-Vargas, A. R., Russell, P., Schauer, J. J., Stevens, P. S., Volkamer, R., and Zavala, M.: An overview of the MILAGRO 2006 Campaign: Mexico City emissions and their transport and transformation, Atmos. Chem. Phys., 10, 8697-8760, doi:10.5194/acp-10-8697-2010, 2010.

Murphy, J. G., Day, D. A., Cleary, P. A., Wooldridge, P. J., and Cohen, R. C.: Observations of the diurnal and seasonal trends in nitrogen oxides in the western Sierra Nevada, Atmos. Chem. Phys., 6, 5321-5338, doi:10.5194/acp-6-5321-2006, 2006.

Nizkorodov, S. A., Harmon, C. W., Grimm, R. L., McIntire, T. M., Peterson, M. D., Njegic, B., Angel, V. M., Alshawa, A., Underwood, J. S., Tobias, D. J., Gerber, R. B., Gordon, M. S., and Hemminger, J. C.: Hygroscopic Growth and Deliquescence of
$\mathrm{NaCl}$ Nanoparticles Mixed with Surfactant SDS, J. Phys. Chem. B, 114, 2435-2449, 2010.

Noziere, B., Dziedzic, P., and Cordova, A.: Formation of secondary light-absorbing "fulvic-like" oligomers: A common process in aqueous and ionic atmospheric particles?, Geophys. Res. Lett., 34, L21812 doi:10.1029/2007g1031300, 2007.

Petters, M. D. and Kreidenweis, S. M.: A single parameter representation of hygroscopic growth and cloud condensation nucleus activity, Atmos. Chem. Phys., 7, 1961-1971, doi:10.5194/acp-71961-2007, 2007.

Seber, G. A. F.: Multivariate Observations, John Wiley \& Sons, I., Hoboken, NJ, 1984.

Setyan, A., Zhang, Q., Merkel, M., Knighton, W. B., Sun, Y., Song, C., Shilling, J. E., Onasch, T. B., Herndon, S. C., Worsnop, D. R., Fast, J. D., Zaveri, R. A., Berg, L. K., Wiedensohler, A., Flowers, B. A., Dubey, M. K., and Subramanian, R.: Characterization of submicron particles influenced by mixed biogenic and anthropogenic emissions using high-resolution aerosol mass spectrometry: results from CARES, Atmos. Chem. Phys., 12, 8131-8156, doi:10.5194/acp-12-8131-2012, 2012.

Shaw, W. J., Pekour, M. S., Coulter, R. L., Martin, T. J., and Walters, J. T.: The daytime mixing layer observed by radiosonde, profiler, and lidar during MILAGRO, Atmos. Chem. Phys. Discuss., 7, 15025-15065, doi:10.5194/acpd-7-15025-2007, 2007.

Singh, H. B., Brune, W. H., Crawford, J. H., Flocke, F., and Jacob, D. J.: Chemistry and transport of pollution over the Gulf of Mexico and the Pacific: spring 2006 INTEX-B campaign overview and first results, Atmos. Chem. Phys., 9, 2301-2318, doi:10.5194/acp-9-2301-2009, 2009.

Spath, H.: Cluster Dissection and Analysis: Theory, FORTRAN Programs, Examples, Halsted Press, New York, 1985.

Steiner, A. L., Cohen, R. C., Harley, R. A., Tonse, S., Millet, D. B., Schade, G. W., and Goldstein, A. H.: VOC reactivity in central California: comparing an air quality model to ground-based measurements, Atmos. Chem. Phys., 8, 351-368, doi:10.5194/acp-8351-2008, 2008.

Sullivan, R. C., Petters, M. D., DeMott, P. J., Kreidenweis, S. M., Wex, H., Niedermeier, D., Hartmann, S., Clauss, T., Stratmann, F., Reitz, P., Schneider, J., and Sierau, B.: Irreversible loss of ice nucleation active sites in mineral dust particles caused by sulphuric acid condensation, Atmos. Chem. Phys., 10, 1147111487, doi:10.5194/acp-10-11471-2010, 2010.

Takahama, S., Gilardoni, S., Russell, L. M., and Kilcoyne, A. L. D.: Classification of multiple types of organic carbon composition in atmospheric particles by scanning transmission $\mathrm{X}$ ray microscopy analysis, Atmos. Environ., 41, 9435-9451, doi:10.1016/j.atmosenv.2007.08.051, 2007.

Vicars, W. C. and Sickman, J. O.: Mineral dust transport to the Sierra Nevada, California: Loading rates and potential source areas, J. Geophys. Res.-Biogeo., 116, G01018, doi:10.1029/2010JG001394, 2011.

Volkamer, R., Jimenez, J. L., San Martini, F., Dzepina, K., Zhang, Q., Salcedo, D., Molina, L. T., Worsnop, D. R., and Molina, M. J.: Secondary organic aerosol formation from anthropogenic air pollution: Rapid and higher than expected, Geophys. Res. Lett, 33, L17811, doi:10.1029/2006GL026899, 2006.

Wang, B., Laskin, A., Roedel, T., Gilles, M. K., Moffet, R. C., Tivanski, A., and Knopf, D. A.: Heterogeneous ice nucleation and water uptake by field-collected atmospheric par- 
ticles below 273 K, J. Geophys. Res.-Atmos., 117, D00V19, doi:10.1029/2012JD017446, 2012.

Wittmaack, K.: Brochosomes produced by leafhoppersa widely unknown, yet highly abundant species of bioaerosols in ambient air, Atmos. Environ., 39, 1173-1180, doi:10.1016/j.atmosenv.2004.11.003, 2005.

Yu, X.-Y., Cary, R. A., and Laulainen, N. S.: Primary and secondary organic carbon downwind of Mexico City, Atmos. Chem. Phys., 9, 6793-6814, doi:10.5194/acp-9-6793-2009, 2009.

Zaveri, R. A., Berkowitz, C. M., Brechtel, F. J., Gilles, M. K., Hubbe, J. M., Jayne, J. T., Kleinman, L. I., Laskin, A., Madronich, S., Onasch, T. B., Pekour, M., Springston, S. R., Thornton, J. A., Tivanski, A. V., and Worsnop, D. R.: Nighttime chemical evolution of aerosol and trace gases in a power plant plume: Implications for secondary organic nitrate and organosulfate aerosol formation, $\mathrm{NO}_{3}$ radical chemistry, and $\mathrm{N}_{2} \mathrm{O}_{5}$ heterogeneous hydrolysis, J. Geophys. Res.-Atmos., 115, D12304, doi:10.1029/2009JD013250, 2010.
Zaveri, R. A., Shaw, W. J., Cziczo, D. J., Schmid, B., Ferrare, R. A., Alexander, M. L., Alexandrov, M., Alvarez, R. J., Arnott, W. P., Atkinson, D. B., Baidar, S., Banta, R. M., Barnard, J. C., Beranek, J., Berg, L. K., Brechtel, F., Brewer, W. A., Cahill, J. F., Cairns, B., Cappa, C. D., Chand, D., China, S., Comstock, J. M., Dubey, M. K., Easter, R. C., Erickson, M. H., Fast, J. D., Floerchinger, C., Flowers, B. A., Fortner, E., Gaffney, J. S., Gilles, M. K., Gorkowski, K., Gustafson, W. I., Gyawali, M., Hair, J., Hardesty, R. M., Harworth, J. W., Herndon, S., Hiranuma, N., Hostetler, C., Hubbe, J. M., Jayne, J. T., Jeong, H., Jobson, B. T., Kassianov, E. I., Kleinman, L. I., Kluzek, C., Knighton, B., Kolesar, K. R., Kuang, C., Kubátová, A., Langford, A. O., Laskin, A., Laulainen, N., Marchbanks, R. D., Mazzoleni, C., Mei, F., Moffet, R. C., Nelson, D., Obland, M. D., Oetjen, H., Onasch, T. B., Ortega, I., Ottaviani, M., Pekour, M., Prather, K. A., Radney, J. G., Rogers, R. R., Sandberg, S. P., Sedlacek, A., Senff, C. J., Senum, G., Setyan, A., Shilling, J. E., Shrivastava, M., Song, C., Springston, S. R., Subramanian, R., Suski, K., Tomlinson, J., Volkamer, R., Wallace, H. W., Wang, J., Weickmann, A. M., Worsnop, D. R., Yu, X.-Y., Zelenyuk, A., and Zhang, Q.: Overview of the 2010 Carbonaceous Aerosols and Radiative Effects Study (CARES), Atmos. Chem. Phys., 12, 7647-7687, doi:10.5194/acp-12-7647-2012, 2012. 